\title{
Atopy affects LPS responsiveness and TLR-4 expression in children peripheral mononuclear cells
}

\author{
D Préfontaine*, AA Banville-Langelier, PO Fiset, J Guay, Q Hamid, BD Mazer ${ }^{*}$ \\ From Canadian Society of Allergy and Clinical Immunology Annual Scientific Meeting 2009 \\ Halifax, Canada. 22-25 October 2009
}

\section{Background}

Lipopolysaccharide (LPS) exposure in early life is associated with a lower incidence of atopy. We sought to determine whether atopy regulates TLR-4 expression and LPS-induced signal transduction on peripheral immune cells e.g. CD4 T 'helper' $\mathrm{T}$ cells, monocytes and $B$ cells of a large pediatric cohort.

\section{Methods}

Over 350 subjects were recruited from the Pediatric Test Center of the Montreal Children's Hospital and a questionnaire was administered to determine presence of a history of atopic diseases. 3-5cc of anti-coagulated blood was taken and peripheral blood mononuclear cells were cultured for up to $24 \mathrm{~h}$ with IL-4 $(13.5 \mathrm{ng} / \mathrm{ml})$ and/ or LPS (up to $5 \mu \mathrm{g} / \mathrm{ml}$ ). We conducted flow cytometric analysis for surface TLR-4 expression, along with $T$ 'helper' lymphocyte marker CD4, pan-B lymphocyte marker CD19, monocyte marker CD14, and for intracellular phosphorylated $\mathrm{p} 44 / \mathrm{p} 42$ and $\mathrm{p} 38$ signaling molecules.

\section{Results}

Non-atopic monocytes prominently internalize TLR-4 and trigger signal transduction (e.g. phosphorylation of p44/p42 and of p38) upon LPS exposure. Such LPS responsiveness was strikingly impaired in monocytes from atopic children. Compared with monocytes, reduced proportions of $\mathrm{CD} 4+{ }_{+}^{\text {High }} \mathrm{T}$ 'helper' lymphocytes and CD19+ B cells express TLR-4. In T cells, TLR-4 expression varies with age (it peaks between 7-17 years of age) and atopy; atopic children display reduced
TLR-4 expression compared with controls. Recombinant IL-4 also interferes with LPS signaling, and was found to differentially modulate TLR-4 expression in $\mathrm{T}$ 'helper', B lymphocytes and monocytes.

\section{Conclusions}

Peripheral TLR $4+$ CD14+CD4+ ${ }^{\text {Low }}$ monocytes may be used to discriminate between atopic and non-atopic children based on reduced LPS-induced signaling in atopic subjects. TLR-4 expression greatly varies with age and appears to be affected by both atopic status and IL4. Our data suggest that atopy and Th2-type immune bias may impair TLR-4-mediated innate immune function during childhood and, therefore influence allergic disease manifestations.

\section{Research funding sources}

AllerGen NCE Inc., J.T. Costello Memorial Research Fund. Fonds de Recherche en Santé du Québec (FRSQ).

Published: 12 May 2010

doi:10.1186/1710-1492-6-S1-P17

Cite this article as: Préfontaine et al:: Atopy affects LPS responsiveness and TLR-4 expression in children peripheral mononuclear cells. Allergy, Asthma \& Clinical Immunology 2010 6(Suppl 1):P17.

\footnotetext{
* Correspondence: bruce.mazer@mcgill.ca

Meakins-Christie Laboratories, Faculty of Medicine, McGill University, 3626 StUrbain Street, Montreal, Qc. Canada H2X 2P2
} 